\title{
A representação temática em documentos arquivísticos: o caso da indexação documental realizada pelos alunos de Arquivologia da UFPB
}

\author{
Thematic representation in archival documents: the case of indexing documentary made by \\ students of Archival UFPB
}

Dulce Elizabeth Lima de Sousa
Bolsista de Iniciação Científica do CNPq/UFPB. Aluna do curso de Graduação em Arquivologia pela UFPB.

E-mail: dulcelizabeth@gmail.com

Pablo Matias Bandeira
Bolsista de Iniciação Científica do CNPq/UFPB. Aluno dos cursos de graduação em Arquivologia e História da
UFPB. E-mail: pablonaba@ ${ }_{\text {hotmail.com }}$

Resumo

A representação temática da informação apresenta instrumentos que almejam a facilitação no processo de sua recuperação e dentre estes destacamos a Indexação, ação proveniente da Biblioteconomia e que ainda encontrase em processo de desenvolvimento técnico-prático na Arquivologia. Assim, Leste trabalho, fazendo uso da pesquisa bibliográfica, embasada em periódicos científicos, repositórios digitais e bibliografia especializada, busca apresentar, como estudo de caso, uma atividade de Indexação em documentos correntes arquivísticos, aplicada a turma de Representação Temática da Informação Arquivística II, do curso de Arquivologia da Universidade Federal da Paraíba (UFPB). Almeja também diferenciar documentos de Arquivos dos documentos de Bibliotecas e comparar os termos selecionados pelos alunos como indexadores com os procedimentos de indexação presentes na oitava área da Norma Brasileira de Descrição Arquivística (NOBRADE). Apresenta como resultante deste trabalho uma Política de Indexação e um Índice, ao qual, este último, posteriormente foi comparado aos termos presentes na NOBRADE, especialmente a oitava área. Acredita-se na criação de padrões aos Arquivos, levando-se em consideração a realidade e as necessidades da Instituição e dos seus usuários.

Palavras-chave: Arquivo. Representação Temática da Informação. Indexação. Norma Brasileira de Descrição Arquivística. NOBRADE.

\begin{abstract}
The thematic representation of information presents tools that aim to facilitate the process of their recovery, and among these we highlight the Indexing, action from the Librarianship and still is in the process of developing technical and practical in Archival. This work, using of literature, grounded in scientific journals, digital repositories and specialized literature, seeks to present as case study, an activity Index in current archival documents, applied to class Thematic Representation Information Archivist II, Archival course of Federal University of Paraiba (UFPB). Also presents differences between documents from the Library and documents from the Archives and compares the terms selected by the students as indexers with the indexing procedures present in the eighth area of the Brazilian Standard Archival Description (NOBRADE). As a result of this investigation presents a Policy Index and an Index, which the latter was subsequently compared to terms present in NOBRADE, especially the eighth area. It is believed the creation of the Archives standards, taking into account the reality and needs of the institution and its users.
\end{abstract}

Keywords: Archive. Thematic Representation of Information. Indexing. Brazilian Standard for Archival Description. NOBRADE. 


\section{Introdução}

O ser humano produz os mais diversos conhecimentos, necessários à realização de suas atividades na sociedade. E para que tais atividades sejam realizadas, existe uma realidade externa a esse conhecimento chamada de informação. Tudo que alegamos conhecer é proveniente da seleção de informações consideradas relevantes. Sendo assim, podemos dizer que o nosso conhecimento é representado a partir das informações selecionadas.

Por meio desta proposição, a informação deve ser ordenada, estruturada, isto é, representada de alguma forma e transmitida por algum canal. Caso contrário, ela pode se tornar inutilizável.

A partir da fala utilizamos as ondas sonoras para transmitir uma mensagem para outra pessoa. Todavia, para a informação, precisamos de um veículo como os sinais, os símbolos e os signos. Além disso, este veículo deve ter um atributo que possa ser compreendido pelo receptor, possibilitando a transmissão de determinada mensagem.

Os sinais são formas de signo que expressam uma ação para atender a necessidade do receptor. O signo, por sua vez, é um indício físico de presença rápida do evento ou coisa que ele representa. Já os símbolos são mais complexos do que os signos, apesar de terem características semelhantes. Os símbolos destinam-se a ter significado além do que materialmente são. Diferente dos signos, os símbolos são apenas representações idealizadas.

Sendo assim, Le Coadic (1996, p.5) define informação como:

[...] um conhecimento inscrito (gravado) sob a forma escrita (impressa ou numérica), oral ou audiovisual. A Informação comporta um elemento de sentido. É um significado transmitido a um ser consciente por meio de uma mensagem inscrita em um suporte espacial-temporal: impresso, sinal elétrico, onda sonora etc. Essa inscrição é feita graça a um sistema de signos (a linguagem), signo este que é um elemento da linguagem que associa um significante a um significado: signo alfabético, palavra, sinal de pontuação.

É considerável que todos esses supracitados são modos de transferência da informação. Entretanto, sabemos que o mais significativo meio de transferência da informação é a linguagem, considerada veículo fundamental da comunicação humana.

A linguagem pode ser considerada como um sistema de ordenação de nossas experiências por meio de duas categorias: a coisa pura e a ação. Gramaticalmente chamamos de substantivo e verbo.

InCID: R. Ci. Inf. e Doc., Ribeirão Preto, v. 3, n. 2, p. 124-141, jul./dez. 2012. 
Direcionando este entendimento para a Ciência da Informação (CI), área do conhecimento que faz uso da informação como matéria prima de estudo, encontramos ações que buscam representar a informação a determinado usuário, objetivando torná-la compreensível ao mesmo e assim atender as suas necessidades.

Podemos usar como exemplo termos como Arquivo, produção de documentos, alunos da Universidade Federal da Paraíba (UFPB) e período 2008.2. Estes termos poderão ter compreensões diferentes se levarmos em consideração as relações entre eles num Sistema de Recuperação da Informação (SRI), além das necessidades dos usuários.

Ao adotarmos o cabeçalho de assunto Arquivo - produção de documentos, percebemos que é formado pela coisa pura e pelo processo (ação). Ainda em pauta o citado cabeçalho de assunto, ao acrescentamos o termo $U F P B$, sem utilizar adjetivo, demonstramos de que Arquivo está sendo falado: Arquivo - produção de documentos - alunos da UFPB. Por fim, temos agora uma subdivisão lógica do Arquivo por composição física, ao acrescentarmos o período 2008.2, para poder distinguir conforme seja um Arquivo de outro lugar, de outros alunos ou de outro período: Arquivo - produção de documentos - alunos da UFPB - período 2008.2 .

Diante disso, observamos que as palavras fazem conexões, pois as unidades lingüísticas não são absolutas, mas sim relacionáveis. É perceptível que uma palavra só exista porque outras a complementam. Assim, podemos observar que todo SRI deve oferecer um mapa de palavras bem relacionadas e que possua uma linguagem compreensível ao seu usuário. Entretanto, para que isso aconteça, determinando a satisfação dos usuários, dependerá de um processo chamado de Representação Temática da Informação, também conhecido como análise da informação, descrição de conteúdo, análise documentária entre outras denominações, ao qual são adotados elementos como símbolos para a sua realização.

De forma ampla, esta forma de representação refere-se ao conteúdo informacional dos documentos e permite a identificação do tema ou do assunto a que se refere. Dentre as ações que propiciam essa referência, destacamos a Indexação, já que os profissionais da informação, como os arquivistas, são os responsáveis pela atribuição desses conceitos aos documentos no momento do processamento técnico de tratamento da informação. Esta atribuição determinará a posterior recuperação de tais conceitos no sistema.

Tomando como base este mesmo pensamento, Aguiar (2008, p.114) defende que: 
Cada vez mais, percebemos que numa estrutura de recuperação de informação, são exigidos meios consistentes para organizar e principalmente representar a informação e o conhecimento. Desse modo, é necessário preocupar-se com as operações que envolvem a indexação, utilizando-se de linguagens de representação da informação e do conhecimento.

Com isso, ao direcionarmos esta discussão a academia, pela importância da indexação para assegurar o sucesso de um SRI, este artigo tem como objetivo maior apresentar uma atividade de Indexação em documentos correntes arquivísticos, aplicada a turma de Representação Temática da Informação Arquivística II, do curso de Arquivologia da UFPB. Além disso, também nos preocupamos em diferenciar documentos de Arquivos dos documentos de Bibliotecas, diferenciação considerada pertinente para a prática da representação documental, e comparar os termos selecionados pelos alunos como indexadores com os procedimentos de indexação presentes na oitava área da NOBRADE.

Apresentadas as informações introdutórias, este trabalho constará de uma explanação sobre Indexação na Representação da Informação; a seguir trataremos da Indexação Arquivística, por meio de diferenças entre a documentação arquivística e a biblioteconômica; na sequência abordaremos a Descrição Arquivística, destacando a Norma Brasileira de Descrição Arquivística (NOBRADE); continuando será apresentado o Percurso Metodológico adotado para a realização desta pesquisa; a seguir serão apresentados os Resultados da Pesquisa; e, por fim, as Considerações Finais.

\section{A indexação representando a informação}

A ação temática da informação que busca, através de termos, descritores, representar os conceitos presentes num determinado documentos, fornecendo ao usuário a informação almejada intitula-se Indexação. Segundo Pinto (1985, p.170) "a indexação consiste na indicação do conteúdo informativo de um documento através da determinação de um ou mais termos que representarão esse conteúdo". Tal procedimento exige do indexador um esforço mental imensurável, pois a subjetividade é uma característica bem acentuada dentro deste procedimento.

Ainda segundo a autora, "a subjetividade interfere no processo de indexação em dois pontos: na determinação do conteúdo informativo dos documentos e na escolha dos termos indexadores representativos deste conteúdo" (PINTO, 1985, p.169). 
O indexador deve extrair conceitos, traduzi-los e definir o tipo de linguagem a ser empregada, a partir de "basicamente das seguintes etapas: Análise dos conceitos e Tradução" (LANCASTER, 2004, p.8-9). Isto é, estas etapas representam "estabelecimento de conceitos tratados e seleção dos que serão indexados, tendo em vista os objetivos do sistema; e tradução dos conceitos selecionados em termos indexadores de acordo com [...] a linguagem de indexação usada no sistema" (PINTO, 1985, p.171).

Para Maia, na Análise do documento, além de levar em consideração o perfil do usuário, devemos também determinar os assuntos do documento a serem indexados a partir da análise dos seguintes elementos: "Título; Palavras-chave (quando houver); Resumos (quando houver); Ficha catalográfica (quando houver); Sumário e índice; Gravuras; Instituição, idiomas, etc..." (MAIA, 2006, p.6).

No caso específico dos Arquivos, dependendo do documento, podem ser observados a sua numeração ou código de identificação, o produtor, o título, o suporte etc. O princípio da proveniência também merece destaque, pois, para Aguiar (2008, p.184) “atuará como um mecanismo para demarcar os significados e assegurar a própria razão de ser de um documento ou conjunto de documentos arquivísticos, garantindo que não se perda de vista suas especificidades orgânico-funcionais".

O princípio da proveniência evitará "a interpretação e qualquer subjectividade que lhe possa estar associada, visto que um documento normalmente tem apenas uma única proveniência" (GAGNON-ARGUIN, 1998, p.85).

Independente dos elementos que serão analisados em um documento, devemos levar em consideração a ação cognitiva e a sua relação com o processo de leitura. Em outras palavras. "a capacidade de reconhecimento; de apreensão; compreensão e de internalização das estruturas significantes de um acervo arquivístico que um indivíduo possui” (AGUIAR, 2008, p.184-185). Sendo assim, conforme Fujita (2006, p.4), a ação cognitiva e a sua relação com o processo de leitura ocorrem:

[...] por realizar, a associação de significados com as diferentes linguagens (a do texto, a do seu conhecimento prévio e a do sistema de informação) para a composição da representação do documento, por certo utiliza elementos da Semântica em um processo cognitivo que precisa do domínio do contexto. 
Enquanto a atividade de indexação temática pressupõe um olhar direcionado para uma unidade documental, como por exemplo, um livro - biblioteca, por outro lado, nos arquivos, deve-se olhar para as características e contextos dos conjuntos documentais, ou seja, "a unidade da análise documentária será um fundo; série e subséries” (AGUIAR, 2008, p.184).

Dentre as resultantes de um conjunto de termos, oriundos da Indexação, destacamos os Índices, que tem como objetivo "principal [...] construir representações de documentos publicados numa forma que se preste a sua inclusão em algum tipo de base de dados" (LANCASTER, 2004, p.1).

Um Índice pode ser definido como "o instrumento mais importante num SRI. Tem sido descrito como a chave para o acesso ao conteúdo dos documentos, ou como uma ponte ou elo entre o conteúdo de um arquivo de informações e seus usuários" (PINTO, 1985, p.170).

Tomando como base os vários elementos subjetivos que influenciam o indexador, como sua experiência de vida, o seu conhecimento sobre determinado assunto entre outros, o resultado da ação de indexação, ou seja, o Índice, pode ter, tanto a presença da Revogação, bem como da Precisão. São exatamente esses dois elementos os usados para medir a eficiência da indexação e do funcionamento de um SRI. Segundo Piedade (1983, p.10), "na avaliação de eficiência de um serviço de recuperação da informação, duas medidas estão diretamente ligadas aos seus índices, o coeficiente re revocação e o coeficiente de precisão".

A relação entre o total de itens úteis e o total de itens recuperados é denominada de coeficiente de precisão. Por outro lado, a relação entre o total de itens úteis encontrados em uma determinada busca e a quantidade total de itens úteis disponíveis num SRI é denominada coeficiente de revocação (FEITOSA, 2006). Por sua vez, Lancaster afirma que se deve usar "revocação [recall] para designar a capacidade de recuperar documentos úteis, e precisão para designar a capacidade de evitar documentos inúteis" (LANCASTER, 2004, p.4).

Quanto mais preciso for o resultado da busca, maior será a especificidade do assunto. Em contrapartida, quanto maior for a revocação, mais exaustivo será o assunto, ou seja, maior será a quantidade de informações recuperadas. Seja qual for o parâmetro utilizado, em suma, a indexação prima que o SRI alcance a satisfação do usuário. Ao ocorrê-la, o profissional da informação conseguiu atingir o seu objetivo, disseminando a informação de forma prática e rápida.

InCID: R. Ci. Inf. e Doc., Ribeirão Preto, v. 3, n. 2, p. 124-141, jul./dez. 2012. 


\section{O caso da indexação arquivística: a documentação arquivística e a biblioteconômica}

Nada do que foi tratado anteriormente é indiferente a Biblioteconomia, mas como um dos objetivos desse trabalho é discutir a representação temática dentro da Arquivologia, precisamos cuidadosamente encontrar indícios mais concretos que possibilitem a entrada da Arquivologia neste campo. Desta forma, a seguir, apresentamos o quadro 1, que apresenta diferenças entre a biblioteca e o arquivo sob a ótica documental:

Quadro 1: Características principais - Bibliotecas e Arquivos

\begin{tabular}{|c|c|c|}
\hline $\mathrm{CO}_{\mathrm{S}}$ & Biblioteca & Arquivo \\
\hline Origem & $\begin{array}{l}\text { Os documentos de Bibliotecas podem } \\
\text { ser compreendidos por meio de seu } \\
\text { primeiro valor, que é o cultural. }\end{array}$ & $\begin{array}{l}\text { Já os documentos de Arquivo são } \\
\text { caracterizados pela relação orgânica } \\
\text { entre si ao logo de aspectos } \\
\text { funcionais, como os de produção e } \\
\text { acumulação documental. O valor } \\
\text { cultural, elemento primário na } \\
\text { Biblioteconomia, é encarado na } \\
\text { Arquivologia como algo secundário, } \\
\text { usado como base histórica para o } \\
\text { Arquivo. }\end{array}$ \\
\hline Aquisição ou custódia & $\begin{array}{l}\text { Documentos colecionados de fontes } \\
\text { diversas, adquiridos por meio de } \\
\text { compra, [permuta] ou doação. } \\
\text { Os documentos podem ter vários } \\
\text { exemplares e a significação do seu } \\
\text { acervo não depende da relação que os } \\
\text { documentos tenham entre si. }\end{array}$ & $\begin{array}{l}\text { Os documentos provêm das } \\
\text { atividades públicas ou privadas. São } \\
\text { produzidos apenas um único } \\
\text { exemplar com um limitado número } \\
\text { de cópias. }\end{array}$ \\
\hline Método de avaliação & $\begin{array}{l}\text { Aplica-se em unidades isoladas. Seu } \\
\text { julgamento não tem caráter } \\
\text { irrevogável e envolve questões de } \\
\text { conveniência e não de preservação. }\end{array}$ & $\begin{array}{l}\text { Preserva-se a documentação referente } \\
\text { a uma atividade, como um conjunto e } \\
\text { seus julgamentos são irrevogáveis. }\end{array}$ \\
\hline Método de classificação & $\begin{array}{l}\text { Utiliza métodos predeterminados e } \\
\text { exigem conhecimento do sistema, do } \\
\text { conteúdo e do significado dos } \\
\text { documentos. }\end{array}$ & $\begin{array}{l}\text { Os arquivos mais se preocupam em } \\
\text { estabelecer uma classificação } \\
\text { especifica (pós-coordenada) ditada } \\
\text { pelas suas particularidades e exige } \\
\text { conhecimento da relação entre as } \\
\text { unidades, a organização e o } \\
\text { funcionamento dos órgãos. }\end{array}$ \\
\hline Método descritivo & $\begin{array}{l}\text { Aplica-se a unidades discriminadas } \\
\text { na biblioteca. Na biblioteca, as séries } \\
\text { (anuários, periódicos etc.) são } \\
\text { unidades isoladas para a catalogação. }\end{array}$ & $\begin{array}{l}\text { Aplica-se a conjuntos de documentos } \\
\text { do arquivo. As séries (órgãos e suas } \\
\text { subdivisões, atividades funcionais ou } \\
\text { grupos documentais da mesma } \\
\text { espécie) são consideradas unidades } \\
\text { para fins de descrição. }\end{array}$ \\
\hline
\end{tabular}

Fonte: Adaptado de Schellenberg (1959 apud PAES, 1997, p.18).

Schellenberg (1973) também esclarece que em alguns casos um documento de biblioteca pode vir a compor um arquivo. Ele cita alguns jornais que a primeira vista seriam documentos de uma biblioteca. Dependendo de quem o acumulou, passa a compor documentos de um arquivo 
As diferenças apresentadas propiciaram muitas discussões na Arquivologia até os tempos atuais. Historicamente, a Arquivologia vem tentando romper o limite técnico e chegar ao desenvolvimento pleno de suas teorias.

Dentro do campo das representações da informação, a representação descritiva encontra-se mais consolidada, se compararmos com a representação temática, necessitando assim a existência de discussões, aos quais podem ser subsidiadas pela descritiva.

Sendo assim, levando-se em consideração a preocupação com a descrição dos acervos, o que é muito importante para conhecer o seu acervo, os arquivistas fazem uso de normas como a NOBRADE. Esta tem sua base estruturada na Norma Geral Internacional de Descrição Arquivística (ISAD(G)). A NOBRADE busca adequar as normas internacionais com a realidade brasileira. Além disso, a citada norma implementa mais uma área de descrição, chamada de Pontos de Acesso e Indexação de Assuntos. Área esta que a própria norma revela a necessidade de se trabalhar com índices para provimento do acesso, foco deste trabalho.

Diante disso, antes de praticarmos a ação temática de indexação e construir a sua resultante, ou seja, um índice, é necessário entender o que significa Descrição Arquivística e a norma NOBRADE, especialmente a oitava área estrutural.

\section{A descrição arquivística}

A Descrição Arquivística tem a intenção de identificar e esclarecer o contexto e o conteúdo de documentos, com a finalidade de promover um benéfico acesso aos arquivos de um modo geral. Por meio dos instrumentos de pesquisa, a descrição arquivística caracteriza os documentos de arquivo quanto a sua gestão, identificação e localização.

Segundo Souza et al. (2006, p.40), "ela situa o pesquisador quanto ao contexto e o sistema de arquivo que o gerou". A Descrição Arquivística é o ato de descrever e representar informações contidas em documentos e/ou fundos de arquivo. Essa descrição possibilita a criação de instrumentos de pesquisa.

A Descrição Arquivística, no final da década de 80, ganhou uma forte atenção internacional. Diante desse patamar, o Canadá propôs ao Conselho Internacional de Arquivos (CIA), no ano de 1988, a criação de normas internacionais de descrição. O primeiro 
documento elaborado pela Comissão responsável pela criação foi à $\operatorname{ISAD}(G)$, a qual foi publicada em 1994 para abranger documentos de qualquer suporte.

A $\operatorname{ISAD}(\mathrm{G})$ tem um alto grau de generalidade, definindo apenas a macroestrutura da descrição arquivística e indexação de documentos, deixando a definição quanto a procedimentos específicos para outras esferas decisão, nacionais ou institucionais (NOBRADE, 2006, p.8).

Em 1996, foi lançada para complementar à $\operatorname{ISAD}(\mathrm{G})$, a Norma Internacional de Registro de Autoridade Arquivística para Entidades Coletivas, Pessoas e Famílias (ISAAR(CPF)), a qual possui metodologias já utilizadas na Biblioteconomia, sendo estas o intercâmbio de descrições ente instituições, sistemas e redes; a compreensão dos usuários quanto ao contexto da produção dos documentos e seus significados, ao acesso dos documentos com base nas descrições; e a identificação precisa dos produtores e dos documentos. Apenas em 1998 o Arquivo Nacional publicou gratuitamente a primeira edição da $\operatorname{ISAD}(\mathrm{G})$ e da ISAAR(CPF). Além disso, a Instituição aproveitou a oportunidade para promover eventos que discutissem a $\operatorname{ISAD}(\mathrm{G})$, pois se iniciavam os debates internacionais.

Nestes debates, o Brasil entrou como pais membro das discussões de revisão da ISAD $(G)$, por meio do Arquivo Nacional. A partir dessa discussão, é criada a NOBRADE, que tem o objetivo adaptar as normas internacionais à realidade brasileira, ou seja, uma versão brasileira da $\operatorname{ISAD}(\mathrm{G})$ junto com a ISAAR(CPF), permitindo que os arquivistas possam se basear em normas nacionais.

\section{A NOBRADE e suas implicações na descrição de arquivos}

A NOBRADE visa facilitar o acesso e intercâmbio de informações em âmbito nacional e internacional, garantindo maior qualidade do trabalho técnico. Visa também à economia de recursos aplicados e a otimização das informações recuperadas. E mais, se preocupa com o uso dinâmico e ágil dos instrumentos de pesquisa por parte dos pesquisadores.

Esta norma estabelece diretivas para a descrição no Brasil de documentos arquivísticos, compatíveis com as normas internacionais em vigor $\operatorname{ISAD}(G)$ e ISAAR(CPF), e tem em vista facilitar o acesso e o intercâmbio de informações em âmbito nacional e internacional. Embora voltada preferencialmente para a descrição de documentos em fase permanente, pode também ser aplicada à descrição em fases corrente e intermediária (BRASIL, 2006, p.10). 
Esta norma volta-se para a descrição de documentos na fase permanente, podendo em algumas vezes ser utilizada nas fases correntes e intermediárias. Seus princípios fundamentais são: a descrição geral para o particular, requerer informação relevante para o nível de descrição, estabelecer relações entre as descrições e não inserir informação repetida nos quadros de descrição.

Segundo a NOBRADE (BRASIL, 2006, p.11), seus níveis de descrição estão subdivididos em "acervo da entidade custodiadora (nível 0), fundo ou coleção (nível 1), seção (nível 2), série (nível 3), dossiê ou processo (nível 4) e item documental (nível 5)”.

Já sua estrutura apresenta-se em 8 áreas de acordo com a proposição seguinte: “Área de identificação; Área de contextualização; Área de conteúdo e estrutura; Área de condições de acesso e uso; Área de fontes relacionadas; Área de notas; Área de controle da descrição; Área de pontos de acesso e descrição de assuntos" (BRASIL, 2006, p.18).

Nas 8 áreas de descrição, 28 elementos de descrição estão presentes, porém, apenas 7 são considerados obrigatórios. São eles: "código de referência; título; data(s); nível de descrição; dimensão e suporte; nome(s) do(s) produtor(es); condições de acesso (somente para descrições em níveis 0 e 1)" (BRASIL, 2006, p.19).

Esta área, de pontos de acesso e indexação de assuntos, é assunto de interesse desse artigo, na medida em que nos auxilia na representação temática de documentos arquivísticos. A citada área é fundamental para a recuperação do conteúdo de uma quantidade seleta de elementos de descrição, por meio da elaboração de índices baseado em entradas autorizadas e vocabulário controlado. Além dos pontos de descrição obrigatórios (multinível), cabe a entidade que custodia a documentação identificar outros pontos e estabelecer elementos de descrição relevantes a indexação. Sendo assim, de acordo com a NOBRADE (BRASIL, 2006, p.59):

\footnotetext{
A indexação dos assuntos deve contemplar nomes de entidades, eventos, áreas geográficas, períodos e assuntos tópicos. Os assuntos tópicos devem ser indexados de acordo com as necessidades, possibilidades e objetivos da entidade custodiadora, levando-se em consideração a metodologia e os resultados distintos obtidos pela indexação pré-coordenada, mais comum em sistemas manuais de recuperação de informação, e pela indexação pós-coordenada, mais comum em sistemas informatizados de recuperação de informação.
} 
A aplicação das normas descritivas da NOBRADE contribui para que o intercâmbio de informações seja mais preciso, permitindo o rápido acesso aos documentos. A norma facilita, pelo menos em tese, o trabalho do arquivista, pois são bases fundamentais para se ter um acervo organizado, um usuário satisfeito e uma recuperação da informação mais eficiente.

\section{Percurso metodológico}

Para a realização desta investigação, delineou-se um percurso metodológico que constitui na etapa em que o pesquisador passou a utilizar métodos e técnicas a fim de atingir os objetivos propostos.

Duas etapas compreenderam essa pesquisa: a primeira constituiu-se da pesquisa bibliográfica, que abrangeu a leitura, análise e interpretação de informações presentes em periódicos científicos, repositórios digitais e bibliografia especializada; e a segunda etapa que foi a coleta de dados por meio de uma atividade de Indexação em documentos correntes arquivísticos.

O professor da disciplina Representação Temática da Informação Arquivística II, do período 2010.1, do curso de Arquivologia, da UFPB, partiu da premissa de que a teoria vista em sala de aula deve ser posta em prática, especialmente no que se refere à Indexação apresentada pela NOBRADE.

Neste sentido, selecionamos os alunos da referida disciplina. Do total de 18 alunos, 12 participaram, formando o corpus da pesquisa. A esses alunos foi aplicada a referida atividade, no dia 30 de julho do mesmo ano. O documento em questão foi o Plano de Curso da mesma disciplina. Os alunos deveriam selecionar os termos mais representativos do citado documento por meio da indexação. Em seguida, realizar a mesma atividade tomando como base a oitava área da NOBRADE: área de pontos de acesso e indexação de assuntos.

Após a atividade, foi exigida a elaboração de um Índice Único, haja vista os diferentes termos selecionados entre os participantes da pesquisa, conforme será apresentado no item a seguir. 


\section{Resultados da pesquisa}

No primeiro momento da atividade, o Índice apresentou 39 termos. Conforme se observa no quadro (2) abaixo, os termos que obtiveram maior frequência de repetição, sendo por 5 vezes, foram Ementa e Indexação. Ambos podem ser considerados representativos ao documento (Plano de Curso), ao ambiente de pesquisa (curso de Arquivologia - UFPB) e aos pesquisados (alunos da disciplina Representação Temática da Informação Arquivística II).

Quadro 2: Índice elaborado pelos alunos - primeira parte da atividade
\begin{tabular}{|l|l|}
\hline \multicolumn{2}{|c|}{ Termos } \\
\hline $4^{\circ}$ Período & Informação \\
\hline Análise de Assunto & Linguagem Controlada \\
\hline Arquivística & Linguagem Natural \\
\hline Arquivologia & Metodologias \\
\hline Arquivos & Objetivos \\
\hline Arquivos Permanentes & Princípios \\
\hline Aspectos conceituais & Prof. Márcio Bezerra da Silva \\
\hline Avaliação & Recuperação da Informação \\
\hline Bibliografia & Representação Temática \\
\hline Classificação de Documentos & Representação Temática da Informação Arquivística \\
\hline Conteúdo & Sistema Pós-Coordenado \\
\hline Conteúdo Programático & Sistema pós-coordenado em Arquivo \\
\hline Diretrizes & Sistemas Automatizados \\
\hline Disciplina & Sistemas de Recuperação da Informação \\
\hline Documento Impresso & Técnicas \\
\hline Documentos & Tesauro \\
\hline Ementa & UFPB \\
\hline Indexação & Unitermo \\
\hline Indexação Pós-Coordenada & Universidade Federal da Paraíba \\
\hline Índice & \\
\hline
\end{tabular}

Fonte: Atividade de Indexação em documentos correntes arquivísticos - curso de Arquivologia/UFPB.

No segundo momento ocorreu a realização de uma nova indexação tomando como base a oitava área da NOBRADE: área de pontos de acesso e indexação de assuntos. Esta é formada por 11 subitens, aos quais foram consultadas para a elaboração do Índice Único:

- 8.1.1 - Atendendo as orientações do subitem, o trabalho foi elaborado através da descrição no nível cinco, que por conseqüência atendeu as exigências desta pesquisa;

- 8.1.2 - Nem todos os alunos conseguiram cumprir essa orientação. Do total de pesquisados, apenas 1 identificou o Produtor. No documento analisado, não existe um título em destaque, ou seja, o mesmo começa pela por "1. Ementa”, “2. Objetivos” e assim por diante, o que nos leva a pensar que o título poderia ser Plano de Aula ou Ementa. Se considerarmos que o nome Ementa é o título, então 5 alunos identificaram 
o título. Se não considerarmos que Ementa é o título e a considerarmos como a Espécie Documental, então nenhum aluno conseguir extrair o título do documento;

- 8.1.3 - Neste subitem, deve-se consultar orientações da norma ISAAR(CPF), por meio de fontes de referência como o Código de Catalogação Anglo-Americano/2a edição (AACR2) e a Associação Brasileira de Normas Técnicas (ABNT), para índices que constem os produtores. Sendo assim, ao levarmos em consideração Prof. Márcio Bezerra da Silva, 2 alunos adotaram Silva, Márcio Bezerra e o restante, 10 alunos, não realizaram qualquer alteração;

- 8.1.4 - Recomenda-se a modernização dos nomes, ao procurar reter outras formas de grafia explicitadas nos documentos. Esta modernização deve ocorrer por meio de consulta ao vocabulário da Academia Brasileira de Letras. Com isso, salientamos que no curso de Biblioteconomia e Arquivologia da UFPB, o termo Indexação PósCoordenada vem sendo substituído por Representação Temática da Informação II, por considerar o termo mais condizente a realidade acadêmica. Termo este que intitulada a disciplina presente nesta pesquisa;

- 8.1.5 - Neste subitem, o título entra como objeto de indexação no nível cinco. Entretanto, como existe uma imprecisão no título do documento em pauta, 8 alunos recorreram ao item 1.2 Título, subitem 1.2.3, pois este determina que títulos originalmente imprecisos devem ser complementados, para que se alcance maior precisão. Com isso, para esses 8 alunos, o título do documento deve ser Ementa da Disciplina Representação Temática da Informação Arquivística II;

- 8.1.6 - O subitem em questão fala que quando o elemento Título (1.2) estiver acompanhado das respectivas indicações de responsabilidade, os nomes indicados devem seguir orientações básicas da norma ISAAR(CPF), no que diz respeito às formas autorizadas de entrada dos nomes. Com isso, todos os alunos entenderam que os subitens 8.1.3 e 8.1.5 atenderiam a essa questão;

- 8.1.7 - Todos os alunos adotaram o termo Documento Impresso por se adequar a este subitem, ou seja, informações do suporte. Documento este entregue em sala de aula;

- 8.1 .8 - Neste subitem, os alunos atenderam essa orientação, ao quais os termos estão em uma linguagem controlada. Com não foi proposto nesta pesquisa, nenhum aluno construiu um tesauro. Conforme podemos observar, os termos Análise de Assunto e Técnicas passaram a ser representado por Indexação; os termos Arquivística, Arquivo e Arquivo Permanente passaram a ser representados por Arquivologia; o termo 
Conteúdo passou a ser representado por Conteúdo Programático; os termos Avaliação, Bibliografia, Disciplina, Documentos, Metodologias e Objetivos passaram a ser representados por Ementa; o termo Sistema Pós-Coordenado passou a ser representado por Sistema Pós-Coordenado em Arquivo; e, por fim, o termo UFPB passou a ser representado por Universidade Federal da Paraíba. Sendo assim, conforme o uso da linguagem controlada, um único termo passou a representar vários termos inicialmente presentes de forma natural;

- 8.1.9 - Como neste subitem, a indexação do título deve levar em consideração categorias como nomes das entidades, todos os alunos usaram o termo Universidade Federal da Paraíba;

- 8.1.10 - Assim como ocorreu no subitem anterior, sendo que neste caso refere-se aos termos em geral selecionados, ao ser levado em consideração a categoria entidade, todos os alunos usaram o termo Universidade Federal da Paraíba;

- 8.1.11 - Nenhum termo presente no segundo Índice apresenta informações à identificação de normas e convenções em que a descrição foi baseada. Neste caso, a NOBRADE seria o termo a ser usado.

Diante da indexação realizada com base na oitava área da NOBRADE, de um total de 39 termos, o Índice Único passou a ser formado por 19 termos, sendo o termo Indexação citado por todos os alunos, conforme segue no quadro 3:

Quadro 3: Índice elaborado pelos alunos com base na NOBRADE - segunda parte da atividade

\begin{tabular}{|l|l|}
\hline \multicolumn{2}{|c|}{ Termos } \\
\hline Arquivologia & Recuperação da Informação \\
\hline Conteúdo Programático & Representação Temática \\
\hline Documento Impresso & Representação Temática da Informação Arquivística II \\
\hline Ementa da disciplina Rep. Tem. Da Inf. Arq. II & Sistema pós-coordenado em Arquivo \\
\hline Indexação & Sistemas Automatizados \\
\hline Indexação Pós-Coordenada & Sistemas de Recuperação da Informação \\
\hline Índice & Tesauro \\
\hline Linguagem Controlada & Unitermo \\
\hline Linguagem Natural & Universidade Federal da Paraíba \\
\hline Prof. Márcio Bezerra da Silva & \\
\hline
\end{tabular}

Fonte: Atividade de Indexação em documentos correntes arquivísticos - curso de Arquivologia/UFPB.

Com base neste resultado, percebemos a necessidade do uso de normas, padrões, para a realização da Indexação. Estes padrões podem ajudar a diminuir a subjetividade, presentes nesta atividade. Sendo assim, o desenvolvimento de uma Política de Indexação torna-se fundamental para a gestão arquivística. Para se estabelecer uma Política de Indexação, segundo Cesarino (1985, p. 165), primeiramente devem ser observados os seguintes itens: 
- Identificação das características do usuário (áreas de interesse, nível, experiência, atividades que exercem);

- Volume e características da literatura a ser integrada ao sistema;

- Volume e características das questões propostas pelo usuário;

- Número e qualidade dos recursos humanos envolvidos;

- Determinação dos recursos financeiros disponíveis para criação e manutenção do sistema;

- Determinação dos equipamentos disponíveis.

Depois de observados os itens citados anteriormente, na elaboração de uma Política de Indexação, conforme Carneiro (1985), os seguintes elementos devem estar presentes:

- Cobertura de assuntos;

- Seleção e aquisição dos documentos-fonte;

- Definição no processo de indexação: níveis de exaustividade (revocação) e especificidade (precisão), e linguagem de indexação livre ou controlada;

- Elaboração de estratégias de busca;

- Estudos sobre o tempo de resposta do sistema;

- Determinação da forma de saída dos resultados da busca;

- Avaliação do sistema.

Sendo assim, ao perceber a importância da Política de Indexação para a gestão arquivística, compreendemos que as ações propostas por Carneiro (1985) devem ser adotadas, pois estas guiarão os arquivistas na tomada de decisões e na otimização dos serviços oferecidos aos usuários, principalmente na recuperação da informação.

\section{Considerações finais}

Esta pesquisa nos mostrou a necessidade de estudos sobre a prática da Indexação nos Arquivos. Esta é uma ação que está diretamente ligada a recuperação da informação pelos usuários. Caso esta ação apresente problemas, seja pela escolha incorreta de termos, seja por realizar uma tradução de termos não compreensíveis aos usuários, a recuperação não obterá sucesso. 
A Indexação, bem como Representação Temática da Informação, na Arquivologia, não apresentam teorias e fundamentos se compararmos a Representação Descritiva, ao qual se encontra consolidada. Dentre estas teorias e fundamentos Descritivos está a NOBRADE, um dos focos deste trabalho.

Percebemos que a Indexação na Arquivologia deve usar como base as teorias apresentadas na Biblioteconomia, onde se encontra enraizada e muito discutida, inclusive recebendo novas perspectivas a partir dos adventos tecnológicos. Esse é um panorama obtido pela atuação dos alunos e que pode ser um norte para discussões mais amplas sobre o assunto aqui discutido.

Subsidiados pelas explanações apresentadas em sala de aula, ao realizarmos a atividade de Indexação em documentos correntes arquivísticos, na turma Representação Temática da Informação Arquivística II, do curso de Arquivologia, período 2010.1, da UFPB, percebemos que a ausência de uma Política de Indexação permitirá uma forte subjetividade, ou seja, adoção de inúmeros critérios para a seleção dos termos indexadores.

A partir do momento em que foram adotadas normas da NOBRADE, mais especificamente, a oitava área, houve uma redução significativa na quantidade de termos selecionados, passando de 39 termos, no primeiro índice, para 19 termos, no segundo Índice, intitulado de Índice Único.

Tal resultado nos mostra a importância da criação de padrões, do desenvolvimento de regras, para a realização desta atividade, tão importante para a efetiva recuperação da informação. Em contrapartida, não devemos deixar de levar em consideração a realidade e as necessidades da Instituição e dos seus usuários. E é exatamente neste ponto que acreditamos na importância do desenvolvimento de uma Política de Indexação.

A Política apresentará diretrizes para a construção de Índices específicos para os seus usuários e, consequentemente, para a sua área de atuação. A partir da junção de vários Índices, uma espécie de banco de dados poderia ser formada para a concentração de todos os termos de determinada Instituição, por meio do vocabulário em uso.

Pensar desta forma é dizer que a Política de Indexação é uma decisão administrativa indispensável a um SRI, pois, após o seu desenvolvimento, a Instituição poderá definir as características de suas ações, especialmente a Indexação e a elaboração de um vocabulário controlado.

InCID: R. Ci. Inf. e Doc., Ribeirão Preto, v. 3, n. 2, p. 124-141, jul./dez. 2012. 
Percebemos também que a NOBRADE apresenta grandes contribuições para a realização da indexação. Entretanto, ainda carece de maiores discussões, pois, vários dos termos estabelecidos pelos alunos como pertinentes, não puderam ser acrescentados no Índice Único por não atenderem as exigências das normas.

Estes foram os resultados de uma pesquisa feita junto aos alunos da citada disciplina, os quais são indexadores iniciantes. Tal panorama nos abre a perspectiva de realizar estudos semelhantes com indexadores mais experientes e verificar até que ponto a NOBRADE deve ser discutida com fins de aperfeiçoamento, especialmente em sua oitava área. Assim como a previsão resultante, compartilhamos da necessidade de discussão sobre Indexação na Arquivologia, fortalecendo inferências que nós defendemos e aqui apresentamos quanto ao uso de teorias Biblioteconômicas radicadas e discutidas. Em outras palavras, as inferências feitas pelo professor da disciplina corroboram com a indexação feita pelos alunos.

Esperamos que estudos como esse apresente continuidade. De fato, estudos sobre a Indexação e o desenvolvimento de Política de Indexação devem estar presentes em todos os aspectos documentais, partindo da seleção, até a recuperação da informação.

\section{Referências}

AGUIAR, F. L. O controle de vocabulário controlado como dispositivo metodológico para organização, tratamento e recuperação da informação arquivística. 267 f. 2008. Dissertação (Mestrado em Ciência da Informação) - Pontifícia Universidade Católica de Campinas - PUCC, Campinas, 2008.

BRASIL. CONSELHO NACIONAL DE ARQUIVOS. NOBRADE: Norma Brasileira de Descrição Arquivística. Rio de Janeiro: Arquivo Nacional, 2006. 124p. Disponível em: $<$ www.conarq.arquivonacional.gov.br/Media/publicacoes/nobrade.pdf $>$. Acesso em: 15 jul. 2010.

CARNEIRO, M. V. Diretrizes para uma política de indexação. Revista da Escola de Biblioteconomia da UFMG, Belo Horizonte, v.14. n.2, p. 221-241, set. 1985. Disponível em: < http://portaldeperiodicos.eci.ufmg.br/reb/>. Acesso em: 10 jul. 2010.

CESARINO, M. A. N. Sistemas de recuperação da informação. Revista da Escola de Biblioteconomia da UFMG, Belo Horizonte, v. 14, n. 2, p. 157-168, set. 1985. Disponível em: <http://portaldeperiodicos.eci.ufmg.br/reb/>. Acesso em: 10 jul. 2010.

CONSELHO INTERNACIONAL DE ARQUIVOS. ISAD(G): Norma Geral Internacional de Descrição Arquivística. 2. ed., rev., adotada pelo Comitê de Normas de Descrição, Estocolmo, Suécia, 19-22 de setembro de 1999, versão final aprovada pela CIA. Rio de Janeiro: Arquivo 
Nacional, 2000. 119p. Disponível em:

$<$ http://www.conarq.arquivonacional.gov.br/Media/publicacoes/isad_g_2001.pdf $>$. Acesso em: 09 jul. 2010.

FEITOSA, A. Organização da informação na web: das tags à web semântica. Brasília: Thesaurus, 2006.

FUJITA, M. S. L. Abordagem cognitiva e sócio-cognitiva da leitura documentária na formação inicial do indexador: análise da perspectiva individual em contexto sócio-cultural. In: ENCONTRO NACIONAL DE PESQUISA EM CIÊNCIA DA INFORMAÇÃO, 7., 2006, Marília. Anais... Marília: FFC/UNESP-PUBLICAÇÕES, 2006. p. 1-12.

GAGNON-ARGUIN, L. Os arquivos, os arquivistas e a Arquivística: considerações históricas. In: COUTURE, C.; ROUSSEAU, J-Y. Os fundamentos da disciplina arquivística. Lisboa: Publicações Dom Quixote, 1998. (Nova Enciclopédia, 56).

LANCASTER, F. W. Indexação e resumos: teoria e prática. 2. ed. Brasilia: Briquet de Lemos, 2004.

LE COADIC, Y-F. A ciência da informação. Brasília: Briquet de Lemos/Livros, 1996.

MAIA, C. M. G. Indexação no cotidiano: dicas e sugestões. In: SEMINÁRIO NACIONAL DE BIBLIOTECAS UNIVERSITÁRIAS, 14., 2006, Salvador.

PAES, M. L. Arquivo: teoria e prática. 3. ed., rev. e ampl. Rio de Janeiro: FGV, 1997. 228 p.

PIEDADE, M. A. R. Introdução a teoria da classificação. 2 ed. rev. aum. Rio de Janeiro : Interciência, 1983. $221 \mathrm{p}$.

PINTO, M. C. M. F. Análise e representação de assuntos em sistemas de recuperação da informação: linguagens de indexação. Revista da Escola de Biblioteconomia da UFMG, Belo Horizonte, v. 14, n. 2, p. 169-186, set. 1985. Disponível em:

$<$ http://portaldeperiodicos.eci.ufmg.br/reb/>. Acesso em: 10 jul. 2010.

SHELLEMBERG, T. Arquivos modernos: princípios e técnicas. Rio de Janeiro: Fundação Getúlio Vargas, 1973. 345p.

SOUSA, A. P. M. et al. Princípios da descrição arquivística: do suporte convencional ao eletrônico. Arquivístiva.net, Rio de Janeiro, v.2, n. 2, p 38-51, ago./dez. 2006. 